\title{
Determination of antioxidant activity of gum arabic: An exudation from two different locations
}

\author{
Mohamed E.S. Mirghani ${ }^{\mathrm{a}, \mathrm{b}, *}$, Ahmed A.M. Elnour ${ }^{\mathrm{a}, \mathrm{c}}$, N.A. Kabbashi ${ }^{\mathrm{a}}$, Md Z. Alam ${ }^{\mathrm{a}}$, \\ Khalid Hamid Musa ${ }^{\mathrm{d}}$, Amina Abdullah ${ }^{\mathrm{d}}$ \\ a Bioenvironmental Engineering Research Centre, Biotechnology Engineering, Faculty of Engineering, \\ International Islamic University, Malaysia, PO Box 10, Gombak 50728 Kuala Lumpur, Malaysia \\ b International Institute for Halal Research and Training, International Islamic University Malaysia, \\ PO Box 10, Gombak 50728 Kuala Lumpur, Malaysia \\ c Department of Biochemistry \& Gum Processing, Gum Arabic Research Centre, University of Kordofan, \\ Box 160 Elobied, Sudan \\ d School of Chemical Sciences \& Food Technology, Faculty of Science \& Technology, 43600 UKM, \\ Bangi Selangor, Malaysia
}

*Corresponding author, e-mail: elwathig@iium.edu.my

Received 1 Oct 2016

Accepted 8 Feb 2017

\begin{abstract}
Gum arabic (GA) is the main product of acacia trees. As a raw and commercial samples, GA was extracted with methanol and analysed to measure the antioxidant activity using five methods: 2,2-diphenyl-1-picrylhydrazyl (DPPH), Folin-Ciocalteu indexes (FCI), which indicate total phenolic compounds (TPC), oxygen radical absorbance capacity (ORAC), ferric reducing antioxidant power (FRAP), and cupric reducing antioxidant capacity (CUPRAC). This study used antioxidant assays to detect TPC and selected appropriate and inexpensive methods to determine the antioxidant capacity of GA samples. The results reveal that the FCI, ORAC, and CUPRAC are correlated highly with FRAP. Person's correlation coefficient $(r)$ values are $0.98,0.93$, and 0.99 , respectively, based on the sample size of $(n=8)$. This means that the TPC of GA is highly correlated with their antioxidant activities that are measured by these three methods. Hence the FCI, ORAC, and the CUPRAC methods are more effective and simpler. They had similar predictive power to the FRAP of GA antioxidant activity. Consequently, GA is generally recognized as being slightly acidic which may have been obtained from appropriate methods of the antioxidant capacity detection. This acidity is due to the electronic transfer mechanism based on the selection of the working $\mathrm{pH}$.
\end{abstract}

KEYWORDS: antioxidants, extraction, CUPRAC, FRAP, TPC, DPPH, ORAC

\section{INTRODUCTION}

Various high quality soluble dietary fibres are found in gum arabic (GA), and they are the main products of acacia trees. Sodium, calcium, and potassium salts and other organic compounds are also found with the high-class level in $\mathrm{GA}^{1}$. Although data extraction from antioxidant activities using specialized extraction procedure of GA and its partial products is really difficult, GA could be a valuable source of ingredients for functional foods and other related applications ${ }^{2}$. If GA is presented as a competitive source of phytonutrients, such information or data will become critical. Hence a smart procedure is necessary for quick, reliable, and inexpensive screening process of the antioxidant activity of GA.

GA from Acacia seyal, Acacia polyacantha, and Acacia senegal consists of branched chains of polysaccharides. Polysaccharides are being used to reduce experimental toxicity as it has strong antioxidant properties. Various studies found that GA could improve antioxidant status of the human body by protecting the liver through modulating the expression of oxidative stress genes ${ }^{3}$. On the other hand, there is a lack of studies explaining the proper extraction procedures of the antioxidant compound directly from GA. Hence this study determines various procedures and methods for evaluating the antioxidant level in GA substances. For example, the evaluation of antioxidant activities of natural food compounds or biological systems is conducted by applying various methods which produce various results. In accessing antioxidant activity in vitro, free radical is commonly used, namely, 2-diphenyl 1-picrylhydrazyl $\left(\mathrm{DPPH}^{\circ}\right)$. Compared with a Trolox (water-soluble vitamin E analogue) standard, the 
free radical is generated in the aqueous phase. Measurement of the reduction of yellow-blue $\mathrm{DPPH}^{\circ}$ radical by hydrogen-donating antioxidant is conducted by the suppression of long-wave absorption spectrum of the radical ${ }^{4}$. The procedure is commonly known as the Trolox equivalent antioxidant capacity method. It is a rapid procedure, and it can be used in both aqueous and organic solvent systems for a wide range of $\mathrm{pH}$ values ${ }^{5-7}$. Although it is mentioned in several studies that the method is easy to use, it does not have good repeatability function. Neither the correlation of the method with biological effects nor actual relevance with in vivo antioxidant efficacy is established.

The $\mathrm{DPPH}^{*}$ is a stable free radical and its absorption band is $515 \mathrm{~nm}$. By reducing an antioxidant or a free radical species, the $\mathrm{DPPH}^{{ }^{*}}$ loses its absorption band. To detect antiradical or antioxidant activities of purified phenolic compounds in natural plant extractions, the method is widely used ${ }^{8}$. A study conducted by Bondet, Brand-Williams, and Berset showed that the reaction of the most phenolic antioxidants with the $\mathrm{DPPH}^{\circ}$ is a slow process, and it takes $1-6 \mathrm{~h}$ or longer to reach the steady state ${ }^{9}$. Hence it is recommended that the antioxidant activity should be observed or evaluated from time to time while using the $\mathrm{DPPH}^{\circ}$. The method is used frequently as it has a good repeatability ${ }^{10}$.

To measure the antioxidant capability in protecting proteins from damage caused by free radicals, the ORAC (Oxygen Radical Absorbance Capacity) method could be used as presented in some studies ${ }^{11,12}$. In this study, several generators are utilized in producing three different radicals, which are peroxyl radical $\left(\mathrm{ROO}^{\circ}\right)$, hydroxyl radical $\left(\mathrm{OH}^{*}\right)$, and $\mathrm{Cu}^{2+}$ as a transition metal. Generations of these radicals are vital as the measurement of the antioxidant activity of biological samples depends on oxidant or free radicals ${ }^{13,14}$.

Since ROO ${ }^{\circ}$ is the most commonly used in biological systems, the method was adopted as standard radical ${ }^{15}$. Previous studies considered $\alpha$ phycoerythrin ( $\alpha$-PE) as the target protein, as its loss of fluorescence was an indication of damage from its reaction with peroxyl radical. Practically, the result of the method showed poor repeatability as accredited from the protein interaction with sample polyphenols. In a study conducted by Smina et al, the method was implemented as a new fluorescent substance (fluorescein) to use $\alpha-\mathrm{PE}$ as a probe ${ }^{16}$. Results of this modified method presented much longer time (2-3 times higher) than the actual $\alpha$-PE.

The ORAC method is fully automated and well- standardized which are the major advantages of the method, and the values can also easily be compared in laboratories. The method is also presented as a simulator to phenols antioxidant activity in biological systems as the method reflects a better performance than other while using biologically relevant free radicals to integrate both time and level of antioxidant activity ${ }^{17}$. Conversely, it requires expensive equipment in performing the method. Because of the usages of the expensive equipment, other methods were normally chosen from various types of research, such as CUPRAC (cupric reducing/antioxidant power) ${ }^{18}$, FRAP (ferric reducing antioxidant power) ${ }^{19,20}$, TRAP approach ${ }^{11}$, ABTS for natural radicals ${ }^{21}$, hydroxyl radical searching deoxyribose approach ${ }^{22}$, the DPPH (1,1-diphenyl-2-picrylhydrazyl) ${ }^{23}$, LDL (lipoprotein) oxidation ${ }^{24}$, categorization of lipid peroxidation-based compounds (i.e., thiobarbituric acid reactors) ${ }^{25}$, and reactive nitrogen varieties with biological end-points (i.e., oxidative DNA damage). The main objective of this study is to determine an appropriate method for a rapid performance in extracting, standardizing, and estimating GA antioxidant activity, and its extraction products.

\section{MATERIALS AND METHODS}

\section{Materials}

Neocuproine (2,9-dimethyl-1, 10-phenanthroline) and DPPH (1,1-diphenyl-2-picrylhydrazyl) were purchased from Sigma (St Louis, MO, USA). The FRAP reagent was freshly prepared to contain $1020 \mu \mathrm{l}$ of $300 \mathrm{mM}$ sodium acetate $\mathrm{pH}$ 3.6, $100 \mu \mathrm{l}$ of $10 \mathrm{mM}$ TPTZ (Sigma Chemical), and 6-hydroxy2, 5, 7, 8-tetramethylchroman-2-carboxylic acid (Trolox) and Folin-Ciocalteu phenol reagent (Sigma Chemical Company, Steinheim, Germany), ( \pm )-6hydroxy-2, 5, 7, 8-tetramethylchroman-2-carboxylic acid (TR) (Aldrich Chemicals Company, Steinheim, Germany), ammonium acetate, $\mathrm{CuCl}_{2}$, potassium persulphate, $\mathrm{NaOH}, \mathrm{CuSO}_{4}, \mathrm{Na}_{2} \mathrm{CO}_{3}$, sodium potassium tartrate, $96 \%$ methyl alcohol, and methanol (E. Merck, Darmstadt, Germany). $\mathrm{CuCl}_{2}$ solution $\left(1.0 \times 10^{2} \mathrm{M}\right)$ was prepared by dissolving $0.4262 \mathrm{~g} \mathrm{CuCl}_{2} \cdot 2 \mathrm{H}_{2} \mathrm{O}$ in water, and by diluting

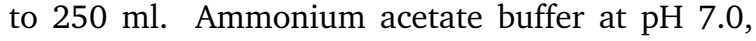
$1.0 \mathrm{M}$ was prepared by dissolving $19.27 \mathrm{~g} \mathrm{NH}_{4} \mathrm{Ac}$ in water and by diluting to $250 \mathrm{ml}$. Neocuproine (Nc) solution $\left(7.5 \times 10^{3} \mathrm{M}\right)$ was prepared daily by dissolving $0.039 \mathrm{~g} \mathrm{Nc}$ in $96 \%$ methanol, and by diluting to $25 \mathrm{ml}$ with methanol. Trolox $\left(1.0 \times 10^{3} \mathrm{M}\right)$ was prepared in $96 \%$ methanol. 
The solutions used in the Folin assay of total phenolics were $2 \%$ aqueous $\mathrm{Na}_{2} \mathrm{CO}_{3}$ in $0.1 \mathrm{M} \mathrm{NaOH}$ (Lowry A), $0.5 \% \mathrm{CuSO}_{4}$ aqueous solution in $1 \%$ $\mathrm{NaKC}_{4} \mathrm{H}_{4} \mathrm{O}_{6}$ solution (Lowry B), and: a freshly prepared mixture of $50 \mathrm{ml}$ Lowry A+ $1 \mathrm{ml}$ Lowry B (Lowry C). Before using the Folin-Ciocalteu reagent, it was diluted with $\mathrm{H}_{2} \mathrm{O}$ at a volume ratio of $1: 3$. In this study, all percentages were presented as $\mathrm{w} / \mathrm{v}$ ratio, and throughout the experiment, distilled de-aerated $\left(\mathrm{N}_{2}\right.$-bubbled) water was utilized. By using Spectro-Star Nano spectrophotometer, all spectrophotometric measurements were conducted with microplate which contains 96 micro-cuvettes.

\section{Samples collection and preparation}

In November 2015, the acacia gum nodules were collected from the Blue Nile and the North Kordofan State of Sudan. After the collection, the experts from Sudanese Ministry of Forestry and Agriculture have examined the samples of acacia gum. This was to ensure that all the samples were identified properly and cleaned from plant bark parts and sand. To make the homogeneity of the samples and random selection of a nodule of GA were divided into two pieces. One piece of the nodule was grounding and made into a mechanical powder using USA standard testing sieve (Fisher Company) with $1.40 \mathrm{~mm}$ mesh size. Then by using Glossaries (DHAUS sensitive balance with $20 \mathrm{ml}$ capacity in each vial), $1 \mathrm{~g}$ of gum powder was measured and $10 \mathrm{ml}$ of absolute methanol was added into each vial. Additionally, all vials which contained samples and solvent were placed into magnetics stirrer (Model: RT 15P; Serial: 2930700$)$. Then the samples were left to rotate for $24 \mathrm{~h}$. Next, by using centrifuge (Mini, China), all extracted samples were centrifuged for $10 \mathrm{~min}$ at a stirring speed of $1000 \mathrm{rpm}$. Furthermore, a filtering process was applied to the clarified suspension by using Sartorius PTEF $0.45 \mu \mathrm{m}$ filter and the supernatants were stored in a freezer below $-25^{\circ} \mathrm{C}$ until the analysis was conducted.

\section{Extraction of antioxidant}

To evaluate the capacity of phenolic extraction as convenient antioxidant from GA as acacia complex group of gum (ACGG), organic solvents were applied. Additionally, two more commercially available gum samples, Almana and Taybat, were exudated from $A$. senegal and $A$. seyal, respectively. Used solvents were acetone, ethanol, and methanol. All the used solvents and chemicals were with their analytical grades. The procedure of solvent extraction was conducted based on the extraction techniques presented in Ref. 26.

First, by using Glossaries DHAUS analytical balance, $1 \mathrm{~g}$ of ACGG dry power was measured precisely. To, investigate the solvent effect on the phenolic compound; each sample was mixed with $10 \mathrm{ml}$ of methanol, ethanol, and acetone. The phenolic compounds were placed in vials and the vials were wrapped with aluminium foil to protect the mixture being spilled off and from lights exposure. The mixture was then shaken for $24 \mathrm{~h}$ at ambient temperature. Finally, by using Sartorius PTEF $0.45 \mu \mathrm{m}$ the ACGG extract was filtered properly. The filtrate was filled into vials and preserved at $-20^{\circ} \mathrm{C}$ until further analytical usages.

\section{Determination of Folin-Ciocalteu index for total phenolic contents (TPC)}

For determination of TPC, the Folin-Ciocalteu Index (FCI) assay was used with slight modifications; the procedure adopted follows the method described by 6 . Approximately $0.5 \mathrm{ml}$ diluted Folin-Ciocalteu reagent was added to $100 \mu \mathrm{l}$ sample extracts and allowed to set for $5 \mathrm{~min}$ before addition of $1 \mathrm{ml}$ $(8 \%)$ of $\mathrm{Na}_{2} \mathrm{CO}_{3}(\mathrm{w} / \mathrm{v})$. The absorbance was taken at $765 \mathrm{~nm}$ wavelength using the spectrophotometer after $2 \mathrm{~h}$, and the result recorded in terms of $\mathrm{mg}$ of gallic acid equivalent.

\section{Radical scavenging activity (DPPH)}

The antioxidant activity was evaluated using a 2,2-diphenyl-1-picrylhydrazyl (DPPH), followed the method in Ref. 4. By using a spectrophotometer (Spectro Nanostar, Germany) at 517 nm wavelength, the DPPH was freshly produced by liquefying $40 \mathrm{mg} \mathrm{DPPH}$ in $1000 \mathrm{ml}$ of methanol to obtain a $1.00 \pm 0.01$ unit of absorbance. Before keeping it in the dark for $2 \mathrm{~h}$, approximately $100 \mu \mathrm{l}$ of sample were mixed up with $1 \mathrm{ml}$ of the DPPH solution. DPPH scavenging activity was determined as $\mathrm{DPPH}_{\text {sc }}=\left(A_{\text {con }}-A_{\text {sample }}\right) / A_{\text {con }}$, where $A_{\text {con }}$ and $A_{\text {sample }}$ represent the absorbance of the control and sample, respectively.

\section{Reducing antioxidant capacity (CUPRAC)}

The procedure of the CUPRAC method is explained in Ref. 27. According to the procedure, $\mathrm{CuCl}_{2}$, neocuproine (2,9-dimethyl-1,10-phenanthroline), ammonium acetate buffer, and water (1 $\mathrm{ml}$ each) were mixed together before adding to the sample $(0.1 \mathrm{ml})$. Against a reagent blank, the absorbance was recorded at $450 \mathrm{~nm}$ of wavelength after $30 \mathrm{~min}$ of the previous step. In this 
case, the UV-Vis spectrophotometer (Nanostar spectrophotometer, USA) was used. Per $100 \mathrm{~g}$ of fresh sample (mg TE/100 $\mathrm{g}$ of $\mathrm{FW}$ ), the result is presented as mg of Trolox Equivalent (TE).

\section{Determination of ferric reducing antioxidant power (FRAP)}

Fresh FRAP reagent was prepared using $300 \mu \mathrm{M}$ acetate buffer, pH 3.6 (3.1 g sodium acetate trihydrate, plus $16 \mathrm{ml}$ glacial acid were mixed up with distilled water as 1:1); $10 \mu \mathrm{M}$ TPTZ (2,4,6-tris (2-pyridyl)-s-triazine), in $40 \mu \mathrm{M} \mathrm{HCl}$; and $20 \mu \mathrm{M}$ $\mathrm{FeCl}_{3} \cdot 6 \mathrm{H}_{2} \mathrm{O}$ with the ratio of $10: 1: 1$ to prepare the working reagent. Then after $30 \mathrm{~min}$, around $1 \mathrm{ml}$ of FRAP reagent was added with $100 \mu \mathrm{l}$ of samples and by using a spectrophotometer, the absorbance was placed at $595 \mathrm{~nm}$ wavelength. The result was presented in mg of Trolox equivalent (TE) as per $100 \mathrm{~g}$ of fresh sample $\left(\mathrm{mg} \mathrm{TE} / 100 \mathrm{~g}\right.$ of FW) ${ }^{28}$.

\section{Oxygen radical absorbance capacity (ORAC)}

The FLUO star Omega microplate fluorescence reader (BMG LABTECH, Offenburg, Germany) was used with an excitation wavelength of $485 \mathrm{~nm}$ and an emission wavelength of $520 \mathrm{~nm}$. 2,2'-azobis(2amidino-propane) dihydrochloride (AAPH), fluorescein, and 6-hydroxy-2,5,7,8-tetramethylchroman-2carboxylic acid (Trolox) were prepared in $75 \mu \mathrm{M}$ phosphate buffer (pH 7.4). Fresh AAPH $(153 \mu \mathrm{M})$ and Trolox $(2 \mu \mathrm{M})$ were prepared when fluorescein $(10 \mathrm{~nm})$ was generated earlier and kept in dark condition at $4{ }^{\circ} \mathrm{C}$. To make $3.125 \mu \mathrm{M}$ to $50 \mu \mathrm{M}$ working solutions, the Trolox standard was mixed in the phosphate buffer. Then, $150 \mu l$ of fluorescein was added to 96-wells plate (Nunc, Thermo Scientific), followed by $25 \mu \mathrm{l}$ of Trolox, buffer (blank), or sample. Then, with the uses of the injector, AAPH $(25 \mu \mathrm{l})$ was injected. By subtracting the AUC of the blank from AUC of a sample, ORAC values were calculated based on net area under the curve (AUC). The value was compared with Trolox standards curve and the result was expressed in micromole ( $\mu \mathrm{mol})$ Trolox equivalents (TE).

\section{Statistical analysis}

By using the same extract, each analysis of antioxidant activity was conducted three times. The differences in antioxidant activities which resulted from these methods were also tested by conducting an ANOVA (MiNITAB software version 17). To determine significant differences, Fisher's new multiple range tests were applied. Among the obtained data, correlations were identified by using Pearson's correlation coefficient $(r)$. For the graphical representation of the identified results, GRAPH PAD PRISM software (version 6) was also used.

\section{RESULTS AND DISCUSSION}

\section{Total phenolic content}

The results of the antioxidant activities were measured in methanol extraction and were expressed as a total phenolic content (TPC). The results were statistically significant $(p \leqslant 0.5)$ different from one another among the acacia complex group of gum. Several examinations were conducted including; FolinCiocalteu reagent index (CFI), radical scavenging activity (DPPH), Copper Reducing Antioxidant Capacity (CUPRAC), ferric reducing antioxidant power (FRAP), and oxygen radical absorbance capacity (ORAC) of antioxidant determination. To identify the optimum methods in extracting the antioxidant activity from gum arabic (GA), all the mentioned methods were applied.

According to Table 1 and Fig. 1, the TPC shows significantly highest $(p \leqslant 0.5)$ antioxidant assay compared with all other samples from two different locations. The ranges of other two samples were found as $11933 \pm 38-2679 \pm 644 \mathrm{mg} \mathrm{GA} / 100 \mathrm{~g}$ for $A$. senegal gum and $1792 \pm 50-3573.6 \pm 5.5 \mathrm{mg}$ GA/100 g for A. seyal gum. The commercial sample (Taybat) was prepared from the same source of A. seyal gum. The result also presents the highest value $(p \leqslant 0.5)$ of antioxidant activity as $72370 \pm 553 \mathrm{mg} \mathrm{GA} / 100 \mathrm{~g}$ DW.

The DPPH value shows slightly different $(p \leqslant$ $0.5)$ from all the tested samples which were identified as ranging from $71.7 \pm 0.3-72.2 \pm 0.7 \mathrm{mg}$ TE/100 g DW for A. senegal gum from Both Locations. The results of the commercial gum samples (Almana and Taybat) also present the highest value $(p \leqslant 0.5)$ in scavenging capacity. The mean values of the results are $30.6 \pm 0.8$ and $33.4 \pm 2.2 \mathrm{mg}$ TE/100 g DW. Statistically, the significant effects $(p \leqslant 0.05)$ of the antioxidant activities between commercial and raw gum samples were observed from different locations.

In this study, the average of the antioxidant capacity is attributed to FRAP. The results presented the values ranging from $162.5 \pm 1.1-$ $119.5 \pm 1.0 \mathrm{mg}$ TE/100 $\mathrm{g}$ for A. senegal gum from the two different locations. In addition, the average of the antioxidant activities of the $A$. seyal gum, A. polyacantha gum, and commercial gum samples (Almana and Taybat) which were calculated using the FRAP assay reflected different val- 
Table 1 Antioxidant activity (mg TE or GA/100 g DW) and total phenolic contents of gum arabic methanol extracts.

\begin{tabular}{|c|c|c|c|c|c|c|c|c|c|c|}
\hline \multirow[t]{2}{*}{ Source } & \multicolumn{2}{|c|}{ DPPH } & \multicolumn{2}{|c|}{ TPC } & \multicolumn{2}{|c|}{ FRAP } & \multicolumn{2}{|c|}{ CUPRAC } & \multicolumn{2}{|c|}{ ORAC } \\
\hline & A & B & A & B & A & B & A & B & A & B \\
\hline A. senegal & $\begin{array}{l}71.7 \\
\pm 0.3\end{array}$ & $\begin{array}{l}72.2 \\
\pm 0.7\end{array}$ & $\begin{array}{c}11933 \\
\pm 38\end{array}$ & $\begin{array}{l}2679 \\
\pm 644\end{array}$ & $\begin{array}{c}162.5 \\
\pm 1.1\end{array}$ & $\begin{array}{l}119.5 \\
\pm 1.0\end{array}$ & $\begin{array}{c}223.6 \\
\pm 1.0\end{array}$ & $\begin{array}{l}211.6 \\
\pm 0.8\end{array}$ & $\begin{array}{l}976.6 \\
\pm 4.8\end{array}$ & $\begin{array}{l}1451 \\
\pm 61\end{array}$ \\
\hline $\begin{array}{l}\text { A. poly- } \\
\text { acantha }\end{array}$ & $\begin{array}{l}36.8 \\
\pm 0.3\end{array}$ & $\begin{array}{l}36.2 \\
\pm 0.8\end{array}$ & $\begin{array}{l}7550 \\
\pm 50\end{array}$ & $\begin{array}{c}1281.3 \\
\pm 5.5\end{array}$ & $\begin{array}{l}375.9 \\
\pm 0.4\end{array}$ & $\begin{array}{l}76.0 \\
\pm 1.0\end{array}$ & $\begin{array}{l}521.7 \\
\pm 1.2\end{array}$ & $\begin{array}{c}132 \\
\pm 1\end{array}$ & $\begin{array}{l}281 \\
\pm 13\end{array}$ & $\begin{array}{l}666 \\
\pm 14\end{array}$ \\
\hline A. seyal & $\begin{array}{l}91.3 \\
\pm 1.1\end{array}$ & $\begin{array}{l}92.3 \\
\pm 0.6\end{array}$ & $\begin{array}{l}1792 \\
\pm 50\end{array}$ & $\begin{array}{c}3573.6 \\
\pm 5.5\end{array}$ & $\begin{array}{c}838 \\
\pm 1\end{array}$ & $\begin{array}{l}176.6 \\
\pm 1.6\end{array}$ & $\begin{array}{c}1025.9 \\
\pm 1.4\end{array}$ & $\begin{array}{c}358.9 \\
\pm 0.2\end{array}$ & $\begin{array}{c}1183.6 \\
\pm 7.1\end{array}$ & $\begin{array}{c}1876.5 \\
\pm 7.3\end{array}$ \\
\hline $\begin{array}{l}\text { Almana } \\
\text { Taybat }\end{array}$ & \multicolumn{2}{|c|}{$30.6 \pm 0.8$} & \multicolumn{2}{|c|}{$3607 \pm 49$} & \multicolumn{2}{|c|}{$37.4 \pm 1.1$} & \multicolumn{2}{|c|}{$46.2 \pm 0.6$} & \multicolumn{2}{|c|}{$469.9 \pm 4.3$} \\
\hline
\end{tabular}

Location A: clay soil (Eldamazine area). Location B: lateritic soil (Kadogli area).

Almana: commercial sample prepared in powder form the source of $A$. senegal gum.

Taybat: commercial sample prepared in powder form from the source of $A$. seyal gum.

$\mathrm{DW}=$ Dry weight. $\mathrm{TE}=$ Trolox equivalent, $\mathrm{GA}=$ Gallic acid.

ues ranging from $838 \pm 1-176.6 \pm 1.6 \mathrm{mg} \mathrm{TE} / 100 \mathrm{~g}$ DW, 375.9 $\pm 0.4-76.0 \pm 1.0 \mathrm{mg} \mathrm{TE} / 100 \mathrm{~g} \mathrm{DW}$, and $37.4 \pm 1.1-721.5 \pm 1.1 \mathrm{mg} \mathrm{TE} / 100 \mathrm{~g} \mathrm{DW}$, respectively.

Statistically, the location shows a significant effect $(p \leqslant 0.05)$ of the antioxidant activity between commercial and raw gum samples. It shows that, locations affect the antioxidant activity $(p \leqslant 0.05)$, as the ORAC contains a high value $(p \leqslant 0.5)$ as $3266 \pm 7 \mu \mathrm{M} \mathrm{TE} / 100 \mathrm{mg}$ DW for Taybat samples compared with that of $A$. seyal and $A$. senegal gum samples, which range from $1184 \pm 7-1877 \pm 7 \mu \mathrm{M}$ TE$/ 100 \mathrm{mg}$ and $976.6 \pm 4.8$ $1451 \pm 61 \mu \mathrm{M}$ TE/100 mg. On the other hand, the antioxidant activity using TPC, CUPRAC, FRAP, and ORAC assays for two different locations were found to be significantly different $(p \leqslant 0.05)$. As no previous studies on gum arabic extraction were found, comparison of the antioxidant extractions of this study was not conducted.

\section{Antioxidant activity recovered by DPPH, FRAP, ORAC and CUPRAC assays}

For a single sample, antioxidant activities were measured for methanol extraction, using FRAP, DPPH, and ORAC assays. To test the reproducibility of the assays, the single extract was measured three times. The best antioxidant activity among all other the assays used in this study are presented by the FCI (TPC) and ORAC assays, while the DPPH, FRAP, and CUPRAC assays are presented differently (Fig. 1). As all techniques produced a comparable ranking of antioxidant activity within each determination time, all assays had no genotype time interaction. Hence to determine antioxidant activity in GA, TPC, and ORAC are assessed could be used as both have shown high antioxidant activities. Conversely, the commercial (Taybat) gum sample shows the most antioxidant recovery, which was followed by $A$. seyal gum from two different locations.

Immediately after generating free radicals, working solutions of the DPPH, FRAP, and CUPRAC were used within $4 \mathrm{~h}^{29}$. The activities of the DPPH, FRAP, TPC, CUPRAC, and ORAC working solutions reacting with GA samples might have been different as the solutions were not in the same age of determination. For example, while using ORAC assay, a 96-wells plate machine (BMG LABTECH, Offenburg, Germany) was used in this study. Values measured were higher at the top compared to the bottom and greater to the left compared with the right of the 96-well plate.

As reported in Ref. 30, a lower coefficient of variance (CV) is obtained when using 48-well than the 96-well plate. The CV of the data generated in 48-wells plate had approximately $50 \%$ of the CV 96-wells plate data. Hence based on the locations of the samples, a growing error rate in the assays was identified. In terms of time and running cost, the main disadvantage of the ORAC method is the necessity of expensive equipment ${ }^{31}$.

On the other hand, the other four methods required very simple machine (a spectrophotometer) which is available, and is commonly used in most laboratories. The advantages of using the three methods (TPC, CUPRAC, and FRAP) were the rapid reaction time, about $2 \mathrm{~h}$ with the samples or about $30 \mathrm{~min}$ with ferric ion. In contrast, the DPPH reaction took much longer time which is about $24 \mathrm{~h}$ in previous studies. Hence GA could be 

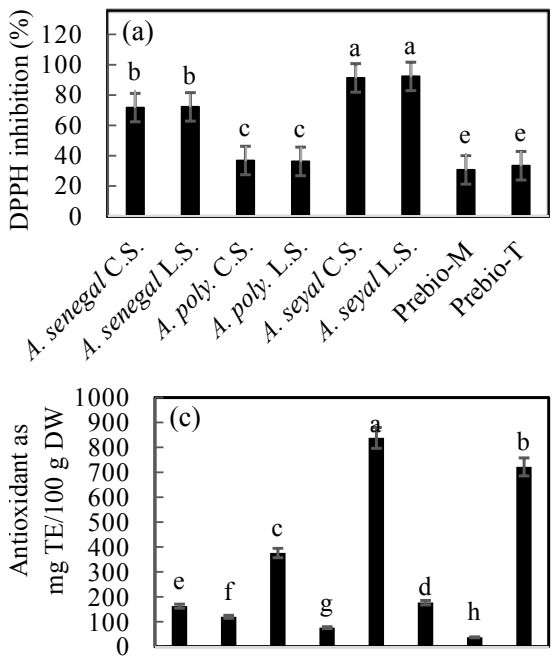

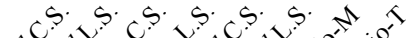
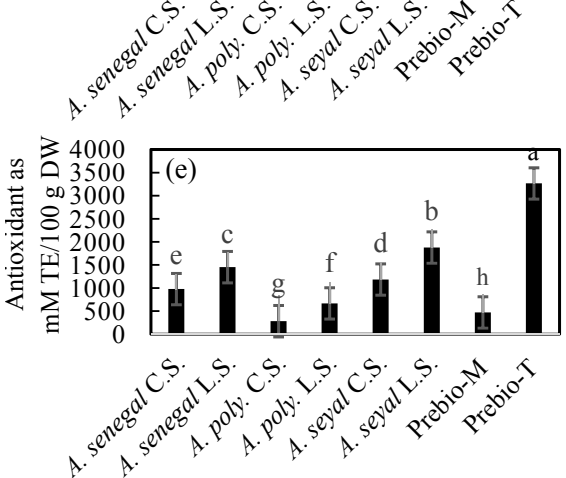
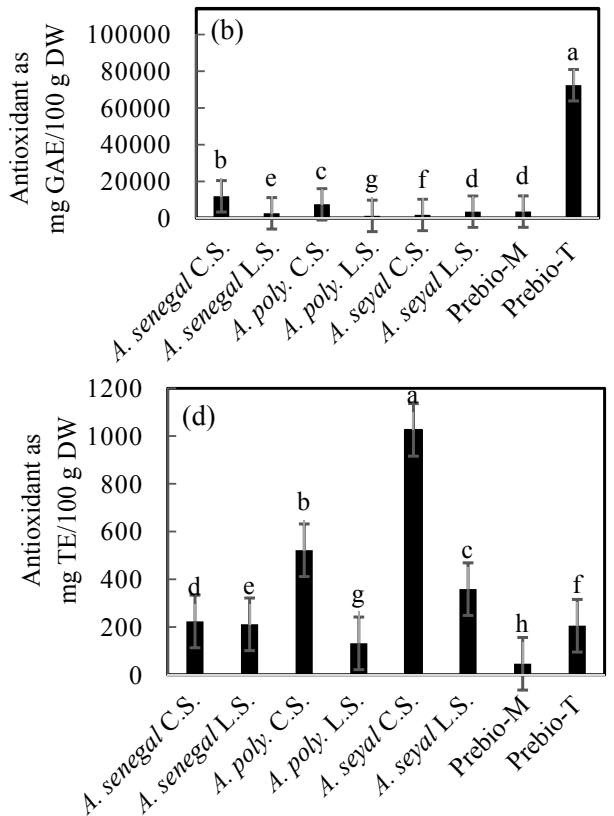

Fig. 1 Gum arabic antioxidant activity of methanol extraction expressed as mg GA or TE/100 g DW: (a) DPPH, (b) TPC, (c) FRAP, (d) CUPRAC, (e) ORAC. C.S.: clay soil, L.S.: lateritic soil.

presented as a natural product which has remarkably high antioxidant activity. Compared with other fruit crops, the antioxidant activities obtained in this study were very high. The antioxidant activities of 12 fresh fruits (pear, melon, apple, tomato, white melon, banana, pink grapefruit, pink grape, kiwi, orange, plum, and strawberry) have been previously reported ranging from less than $1 \mu \mathrm{mol} \mathrm{TE} / \mathrm{g}$ for melon up to $15 \mu \mathrm{mol} \mathrm{TE} / \mathrm{g}$ for strawberry ${ }^{32}$. As determined by FRAP, DPPH and the ORAC assays, the average antioxidant activity of methanol extracted values were $25.2,31.1$, and $21.3 \mu \mathrm{mol} \mathrm{TE} / \mathrm{g}$, respectively.

To reduce the DPPH free radical, aqueous peroxyl radicals, and ferric iron in vitro systems, diverse AOAM levels were found in the assays which may produce a relative change in the attitude of antioxidant compounds in the extracts. Although the interaction between GA and assay was significant for the antioxidant activity of the methanol extraction, it only explained a little quantity of the total variation compared with GA or assay as presented in Table 1 .

\section{Correlations}

Pearson's coefficients are presented in Table 2, indicating the possible correlations between the antioxidant activities of GA and different assays. A correlation assays were conducted among FRAP, DPPH, TPC, CUPRAC, and ORAC, and the obtained antioxidant activities values are presented in Table 2. FRAP, TPC, CUPRAC, and ORAC. The results demonstrate a significant correlation $(p<0.05$ and $p<$

Table 2 Person's correlation coefficients $(r)$ and an antioxidant activity of gum arabic methanol extraction.

\begin{tabular}{lcccc}
\hline & DPPH & FRAP & TPC & ORAC \\
\hline FRAP & $0.37^{\text {ns }}$ & & & \\
TPC (FCI) & $0.48^{\text {ns }}$ & $0.98^{\mathrm{a}}$ & & \\
ORAC & $0.53^{\text {ns }}$ & $0.93^{\mathrm{a}}$ & $0.98^{\mathrm{a}}$ & \\
CUPRAC & $0.42^{\text {ns }}$ & $0.99^{\mathrm{a}}$ & $0.97^{\mathrm{a}}$ & $0.91^{\mathrm{a}}$ \\
\hline
\end{tabular}

a Significant at $p<0.05$ and $0.01 ;{ }^{\text {ns }}$ non-significant. Antioxidant activity measured in methanol extraction is based on the DPPH, FRAP, TPC, and ORAC assays. 
0.01) among different antioxidant activities with a decreasing order of TPC $>$ DPPH. Hence it can be suggested that an antioxidant activity is highly correlated with the TPC than the scavenging power of GA. These results supported the results of other studies ${ }^{33-36}$. The high correlation between FRAP and CUPRAC, TPC and ORAC can establish a fact that, these assays rely on the common reaction mechanism and that there was no significant correlation between DPPH and the values with FRAP, TPC, and CUPRAC. No correlation was previously found between ABTS or DPPH values with ORAC data while applying different phenolic standards ${ }^{37}$. By comparing antioxidant methods of FRAP and CUPRAC (0.99), the maximum Pearson's coefficient was obtained as these two assays were based on similar mechanisms.

\section{CONCLUSIONS}

This study presents the extraction findings from acacia complex groups of gum arabic (ACGG) with remarkable antioxidant activities which are rapidly influenced by the types of assays. The antioxidant extraction depends on the solubility of the antioxidant compounds (of plant material) in the extraction solvent. Hence, an appropriate extraction solvent method, namely, methanol was selected in this study. The selection was made based on a separate study on gum arabic (GA).

This is a pioneer work. In other words, this is the first time an investigation is conducted on the antioxidant activity of the ACGG cultivated in two different locations in Sudan representing clay soil in the Blue Nile area (Eldamazine) and lateritic soil area in North Kordofan (Kadogli), using different stable assays for evaluation. Overall, the FCI, ORAC, and CUPRAC assays are correlated highly with the FRAP assay. This means that the TPC of GA is highly correlated, with statistically significant values. The antioxidant activities were measured by these three methods. Hence the FCI, ORAC, and CUPRAC methods are more effective and simpler. They were used in order to have a similar predictive power as the FRAP of GA antioxidant activity. The findings of this study portray significant and effective measurement of the antioxidant potential benefits, since the cost and time of extraction can be managed to enhance the yield or extraction of new products especially for food and/or pharmaceutical uses.

Acknowledgements: The authors would like to express their gratitude to the University of Kordofan Sudan, Gum Arabic Research Centre, Bioenvironmental Engineering
Research Centre, Department of Biotechnology Engineering at the Faculty (Kulliyyah) of Engineering, International Islamic University Malaysia for providing necessary lab facilities and UKM. For this opportunity, authors also extend the appreciation to Dr Elbasheir Sallam for his significant, continuous, and unlimited financial support.

\section{REFERENCES}

1. Chawla R, Patil G (2010) Soluble dietary fiber. Compr Rev Food Sci Food Saf 9, 178-96.

2. Kong H, Yang J, Zhang Y, Fang Y, Nishinari K, Phillips GO (2014) Synthesis and antioxidant properties of gum arabic-stabilized selenium nanoparticles. Int $J$ Biol Macromol 65, 155-62.

3. Ahmed AA, Fedail JS, Musa HH, Kamboh AA, Sifaldin AZ, Musa TH (2015) Gum Arabic extracts protect against hepatic oxidative stress in alloxan induced diabetes in rats. Pathophysiology 22, 189-94.

4. Musa KH, Abdullah A, Kuswandi B, Hidayat MA (2013) A novel high-throughput method based on the DPPH dry reagent array for determination of antioxidant activity. Food Chem 141, 4102-6.

5. Arnao MB, Cano A, Acosta M (1999) Methods to measure the antioxidant activity in plant material. A comparative discussion. Free Radic Res 31, S89-96.

6. Lemańska K, Szymusiak H, Tyrakowska B, Zieliński R, Soffers AE, Rietjens IM (2001) The influence of $\mathrm{pH}$ on antioxidant properties and the mechanism of antioxidant action of hydroxyflavones. Free Radic Biol Med 31, 869-81.

7. Arabaci B, Gulcin I, Alwasel S (2014) Capsaicin: a potent inhibitor of carbonic anhydrase isoenzymes. Molecules 19, 10103-14.

8. Liang N, Kitts DD (2014) Antioxidant property of coffee Components: Assessment of methods that define mechanisms of action. Molecules 19, 19180-208.

9. Bondet V, Brand-Williams W, Berset C (1997) Kinetics and mechanisms of antioxidant activity using the DPPH. free radical method. LWT Food Sci Tech 30, 609-15.

10. Karabegović IT, Stojičević SS, Veličković DT, Todorović ZB, Nikolić NČ, Lazić ML (2014) The effect of different extraction techniques on the composition and antioxidant activity of cherry laurel (Prunus laurocerasus) leaf and fruit extracts. Ind Crop Prod 54, 142-8.

11. Cao G, Alessio HM, Cutler RG (1993) Oxygen-radical absorbance capacity assay for antioxidants. Free Radic Biol Med 14, 303-11.

12. Sueishi $Y$, Ishikawa M, Yoshioka D, Endoh N, Oowada S, Shimmei M, Fujii H, Kotake Y (2012) Oxygen radical absorbance capacity (ORAC) of cyclodextrinsolubilized flavonoids, resveratrol and astaxanthin as measured with the ORAC-EPR method. $J$ Clin Biochem Nutr 50, 127-32. 
13. Cao G, Sofic E, Prior RL (1996) Antioxidant capacity of tea and common vegetables. J Agr Food Chem 44, 3426-31.

14. Soto-Vaca A, Gutierrez A, Losso JN, Xu Z, Finley JW (2012) Evolution of phenolic compounds from color and flavor problems to health benefits. $J$ Agr Food Chem 60, 6658-77.

15. Niki E (2010) Assessment of antioxidant capacity in vitro and in vivo. Free Radic Biol Med 49, 503-15.

16. Smina TP, Mathew J, Janardhanan KK, Devasagayam TPA (2011) Antioxidant activity and toxicity profile of total triterpenes isolated from Ganoderma lucidum (Fr.) P. Karst occurring in South India. Environ Toxicol Pharmacol 32, 438-46.

17. Prior RL, Wu X, Schaich K (2005) Standardized methods for the determination of antioxidant capacity and phenolics in foods and dietary supplements. J Agr Food Chem 53, 4290-302.

18. Apak R, Güçlü K, Özyürek M, Karademir SE (2004) Novel total antioxidant capacity index for dietary polyphenols and vitamins $\mathrm{C}$ and $\mathrm{E}$, using their cupric ion reducing capability in the presence of neocuproine: CUPRAC method. J Agr Food Chem 52, 7970-81.

19. Benzie IFF, Strain J (1996) The ferric reducing ability of plasma (FRAP) as a measure of "antioxidant power": the FRAP assay. Anal Biochem 239, 70-6.

20. Wayner D, Burton G, Ingold K, Locke S (1985) Quantitative measurement of the total, peroxyl radicaltrapping antioxidant capability of human blood plasma by controlled peroxidation. The important contribution made by plasma proteins. FEBS Lett 187, 33-7.

21. Caillet S, Yu H, Lessard S, Lamoureux G, Ajdukovic D, Lacroix M (2007) Fenton reaction applied for screening natural antioxidants. Food Chem 100, 542-52.

22. Brand-Williams W, Cuvelier M, Berset C (1995) Use of a free radical method to evaluate antioxidant activity. LWT Food Sci Tech 28, 25-30.

23. Gheldof N, Engeseth NJ (2002) Antioxidant capacity of honey from various floral sources based on the determination of oxygen radical absorbance capacity and inhibition of in vitro lipoprotein oxidation in human serum samples. J Agr Food Chem 50, 3050-5.

24. Chumark P, Khunawat P, Sanvarinda Y, Phornchirasilp S, Morales NP, Phivthong-ngam L, Ratanachamnong P, et al (2008) The in vitro and ex vivo antioxidant properties, hypolipidemic and antiatherosclerotic activities of water extract of Moringa oleifera Lam. leaves. J Ethnopharmacol 116, 439-46.

25. Apak R, Özyürek M, Güçlü K, Çapanoğlu E (2016) Antioxidant activity/capacity measurement. 1. Classification, physicochemical principles, mechanisms, and electron transfer (ET)-based assays. J Agr Food Chem 64, 997-1027.

26. Soares AA, de Souza CGM, Daniel FM, Ferrari GP, da Costa SMG, Peralta RM (2009) Antioxidant activity and total phenolic content of Agaricus brasiliensis (Agaricus blazei Murril) in two stages of maturity. Food Chem 112, 775-81.

27. Apak R, Güçlü K, Özyürek M, Celik SE (2008) Mechanism of antioxidant capacity assays and the CUPRAC (cupric ion reducing antioxidant capacity) assay. $\mathrm{Mi}$ crochim Acta 160, 413-9.

28. Musa KH, Abdullah A, Jusoh K, Subramaniam V (2011) Antioxidant activity of pink-flesh guava (Psidium guajava L.): effect of extraction techniques and solvents. Food Anal Meth 4, 100-7.

29. Shahidi F, Zhong Y (2015) Measurement of antioxidant activity. $J$ Funct Foods 18, 757-81.

30. Thaipong K, Boonprakob U, Crosby K, CisnerosZevallos L, Byrne DH (2006) Comparison of ABTS, DPPH, FRAP, and ORAC assays for estimating antioxidant activity from guava fruit extracts. $J$ Food Compos Anal 19, 669-75.

31. Gul HI, Kucukoglu K, Yamali C, Bilginer S, Yuca H, Ozturk I, Taslimi P, et al (2015) Synthesis of 4(2-substituted hydrazinyl)benzenesulfonamides and their carbonic anhydrase inhibitory effects. $J$ Enzym Inhib Med Chem 31, 568-73.

32. Wang H, Cao G, Prior RL (1996) Total antioxidant capacity of fruits. J Agr Food Chem 44, 701-5.

33. Giovanelli G, Buratti S (2009) Comparison of polyphenolic composition and antioxidant activity of wild Italian blueberries and some cultivated varieties. Food Chem 112, 903-8.

34. Moylan S, Berk M, Dean OM, Samuni Y, Williams LJ, O'Neil A, Hayley AC, et al (2014) Oxidative \& nitrosative stress in depression: why so much stress? Neurosci Biobehav Rev 45, 46-62.

35. Edet E, Ofem J, Igile G, Ofem O, Zainab D, Akwaowo G (2015) Antioxidant capacity of different African seeds and vegetables and correlation with the contents of ascorbic acid, phenolics and flavonoids. J Med Plant Res 9, 454-61.

36. Sahu N, Saxena J (2013) Different methods for determining antioxidant activity: a review. Indo $\mathrm{Am} J$ Pharmaceut Res 3, 7025-8.

37. Tabart J, Kevers C, Pincemail J, Defraigne J-O, Dommes J (2010) Evaluation of spectrophotometric methods for antioxidant compound measurement in relation to total antioxidant capacity in beverages. Food Chem 120, 607-14. 